\title{
A synthesis of remote sensing data on Wilkins Ice Shelf, Antarctica
}

\author{
D. G. VAUGHAN \\ British Antarctic Survey, Madingley Road, Cambridge, CB3 OET, U.K.
}

D. R. MANTRIPP

Mullard Space Science Laboratory, University College London, Holmbury St. Mary, Dorking, RH5 6NT, U.K.

\author{
J. SIEVERS \\ Institut für Angewandte Geodäsie, Frankfurt am Main, Germany \\ C. S. M. DOAKE \\ British Antarctic Survey, Madingley Road, Cambridge, CB3 OET, U.K.
}

\begin{abstract}
Wilkins Ice Shelf has an area of $16000 \mathrm{~km}^{2}$ and lies off the west coast of the Antarctic Peninsula bounded by Alexander, Latady, Charcot and Rothschild islands. Several ice shelves, including Wilkins, exist close to a climatic limit of viability. The recent disintegration of the neighbouring Wordie Ice Shelf has been linked to atmopsheric warming observed on the Antarctic Peninsula. The limit of ice-shelf viability thus appears to have migrated south. Should this continue, the question arises; how long will Wilkins Ice Shelf survive?

Compared with the other ice shelves on the Antarctic Peninsula, few surface glaciological data have been collected on Wilkins Ice Shelf. We compare, contrast and combine a variety of remotely sensed data: the recently declassified GEOSAT Geodetic Mission altimetry, Landsat MSS and TM imagery, and radio-echo sounding data (RES), to study its structure and mass balance regime.

We find that this shelf has an unusual mass balance regime and relies heavily for sustenance on in situ accumulation. Its response to a continued atmospheric warming may be significantly different from that of Wordie Ice Shelf. Wordie Ice Shelf was fed by several dynamic outlet glaciers which accelerated the disintegration process when the ice shelf fractured. Wilkins Ice Shelf by contrast is almost stagnant and is expected to respond by normal calving at the ice front. Changes in the accumulation rate or basal melt-rate may, however, dominate any dynamic effect. Over the last two decades the ice front positions have remained stable.
\end{abstract}

\section{INTRODUCTION}

\section{Background}

Mercer (1978) noted that ice shelves on the Antarctic Peninsula exist only up to a climatic limit. He described the breaking up of the most northerly ice shelves as a "sign that a dangerous warming is beginning in Antarctica". Such changes may be taken as robust indicators of climate change.

Morrison (1990) presented mean annual air temperature records for Faraday Base (since 1957) and Marguerite Bay (since 1962) (Fig. 1). A cool period throughout the 1960s was followed by warm periods in the early 1970s and 1980s. Temperatures have risen since 1986 , with 1989 being the warmest year on record in both areas. Simple linear regression of the Faraday mean annual air-temperature record shows an increase of $0.064^{\circ} \mathrm{Ca}^{-1}$ since records began in 1957 ; a total of around $1.5^{\circ} \mathrm{C}$. The statistical significance of this value for long-term trends has been discussed by Sansom (1989).

Doake and Vaughan (1991) observed the progressive

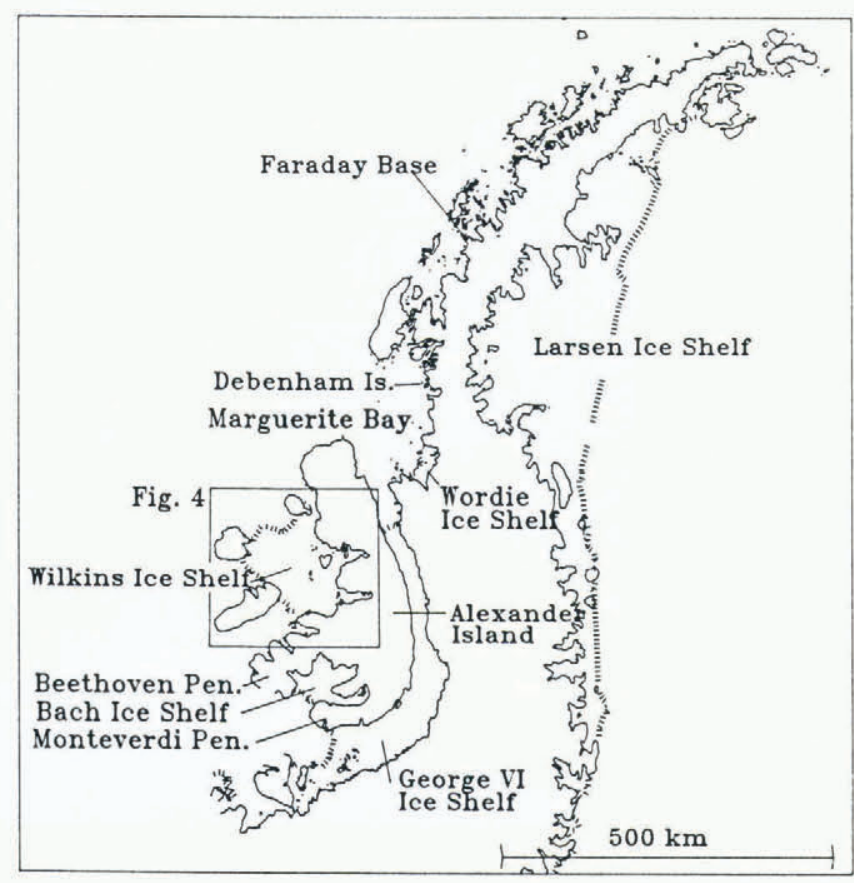

Fig. 1. Location diagram of Antarctic Peninsula. 
disintegration of Wordie Ice Shelf from $2000 \mathrm{~km}^{2}$ in 1966 to $700 \mathrm{~km}^{2}$ in 1989 using Landsat imagery. This rapid disintegration appears to be a direct response to the recorded warming trend which both enhanced fracture processes leading to increased iceberg calving, and reduced the net surface accumulation which previously acted to "glue" an otherwise fragile ice shelf.

The recent disintegration implies that the limit of viability for ice shelves is now south of Wordie Ice Shelf. Reynolds (1981) compiled mean annual temperature measurements in the Antarctic Peninsula normalised to sea level. He showed Wordie Ice Shelf to have a mean annual air temperature of around $-6.5^{\circ} \mathrm{C}$ and Wilkins Ice Shelf (WIS) between $-8^{\circ} \mathrm{C}$ and $-9^{\circ} \mathrm{C}$. Thus a warming at the current rate over the next 30 years would cause the climatic limit to move further south such that at least the northern part of WIS may no longer be viable.

\section{Previous studies}

The only glaciological measurements on WIS were made in the early 1970 s. A measurement of surface velocity was made by resection to the rock outcrops between January 1972 and December 1973, around a site known as J8. The velocity at $\mathrm{J} 8$ was found to be $59.0 \mathrm{~m} \mathrm{a}^{-1}$ in the direction $002^{\circ}$ True.

A hole drilled at $\mathrm{J} 8$, filled with fresh water at $5.5 \mathrm{~m}$ below the surface (Swithinbank, 1988). Temperatures measured in this hole $\left(-2.5^{\circ} \mathrm{C}\right.$ at $\left.10 \mathrm{~m}\right)$ indicate that the ice shelf is close to its melting point.

\section{LANDSAT TMAGERY}

Satellite data provide quantitative topographical information and ground-based and airborne measurements are useful for detailed surveys; high-resolution and visible imagery is, however, unsurpassed for observing structure and flow features in ice masses.

\section{Structural mapping}

The most useful images found were Landsat TM (path/ row) $220 / 109$ and 220/110 taken on 18 February 1986,

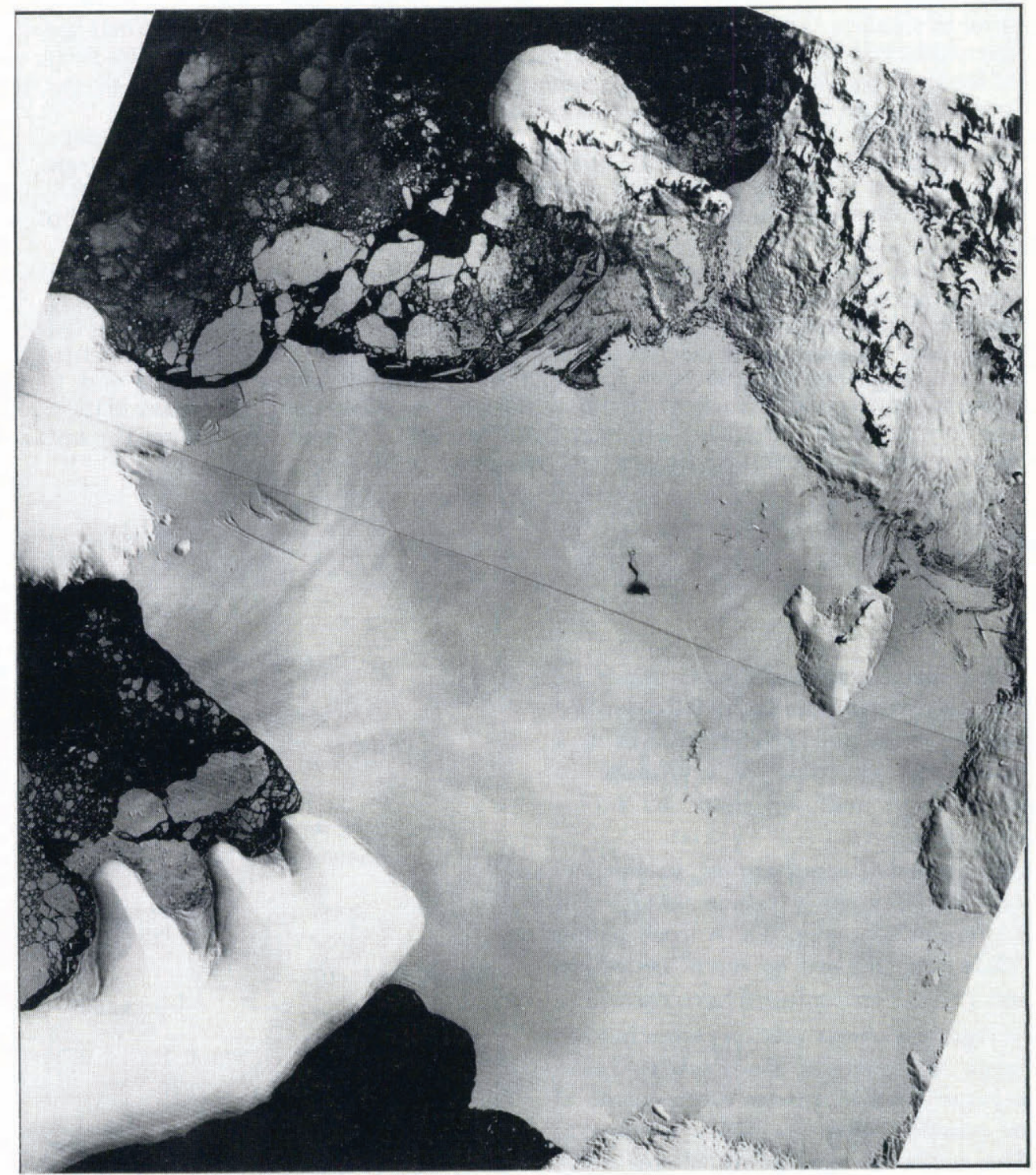

Fig. 2. Landsat imagery of Wilkins Ice Shelf. Landsat images taken on 27 February 1986, path/row numbers 220/109 and 220/110 (published courtesy of EOSAT Ltd). 
and Landsat TM 221/109 and 221/110 taken on 27 January 1990 (Fig. 2.). These images have high spatial resolution $(30 \mathrm{~m})$ and low sun elevation $\left(19^{\circ}\right.$ and $\left.25^{\circ}\right)$, giving good discrimination of surface topography.

Figure 3, showing select features from maps and imagery, includes a number of features on the ice shelf not previously described:

- ice rumples, $\mathrm{A}$ and $\mathrm{B}$,

- numerous ice-shelf flowlines emanating from grounding lines and ice rises/rumples,

- steep slopes marking the extent of the input unit derived from Lewis Ice Field, C,

- ice features, D, E and F, assumed to be small-scale ice-shelf topography related to dynamics,

- location of surface melt pools, K.

Other features were previously noted by Swithinbank (1988) following analysis of Landsat 1 MSS image 231/ 1109 January 1973, including:

- The area of open sea-water G, close to Dorsey Island which remains largely unchanged in the 1986 and 1990 imagery.

- The lake on, or hole in, the ice shelf, $\mathrm{H}$.

The four separate portions of ice front separated by Rothschild, Charcot and Latady Islands have been observed on Landsat imagery over periods of 12 to 18 years. None of the ice fronts shows a significant advance or retreat. The direction of flowlines emanating from ice rumples $\mathrm{A}$ and $\mathrm{B}$ coincide well with measured ice movement at J8. We note that the flowline emerging from ice rumple $\mathrm{A}$ is visible for around $10 \mathrm{~km}$ downstream. Assuming an ice-shelf velocity similar to that measured at J8 (i.e. about $50 \mathrm{~m} \mathrm{a}^{-1}$ ), this is equivalent to around 20 years longevity.

The flowlines emanating from ice rumples $\mathrm{A}$ and $\mathrm{B}$, and the group of ice rumples I, indicate flow in a roughly northerly direction, suggesting that the dominant glacier input is from Lewis Ice Field and perhaps Schubert Inlet. The groups of ice rises at the mouths of Haydn Inlet and Schubert Inlet restriction flow into the ice shelf. WIS thus receives little sustenance from its eastern side and Lewis Ice Field in the south is the dominant input unit.

Gilbert Glacier retains its separate identity as far as Dorsey Island. An open area of sea water $(G)$ is seen at its terminus. Ice from the Gilbert Glacier input must be lost by melting at this point, in a similar way to George VI Ice Shelf (Pearson and Rose, 1983).

To the northwest (i.e. downstream) of ice rumples I and $J$, there are wakes in which we expect the ice to be particularly thin. Such a wake is clearly visible downstream of ice rumples I, but not so clearly downstream of ice rumples $\mathrm{J}$, possibly indicating lower velocities around J.

The lake/hole $\mathrm{H}$ is visible in the same position on the 1973, 1986 and 1990 images. In the 1973 and 1986 images it has a similar shape and extent, but the 1990 image is considerably enlarged. This may be a seasonal fluctuation or may be an indication of changes occurring in the ice shelf.

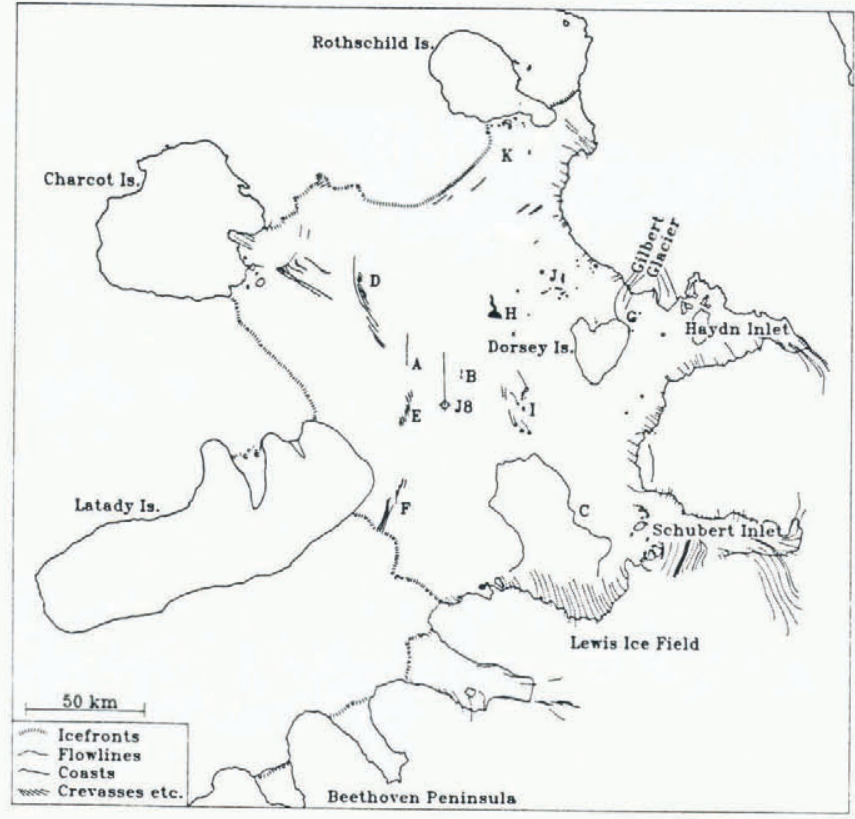

Fig. 3. Structural features of WIS derived from Landsat imagery.

\section{Velocity mapping}

By mapping the displacement of crevasses and melt features using the satellite imagery we have attempted to determine ice-shelf velocity. Unfortunately, such features are sparse and their displacments too small to yield precise velocities. Where they could be measured, velocities were in the range $30-90 \mathrm{~m} \mathrm{a}^{-1}$.

Together with the limited field data, these values suggest that WIS is unusually stagnant compared to Wordie Ice Shelf, where velocities lie between 200 and $2000 \mathrm{~m} \mathrm{a}^{-1}$ (Doake and Vaughan, 1991), and George VI Ice Shelf, where velocities are around $200 \mathrm{~m} \mathrm{a}^{-1}$ (Pearson and Rose, 1983).

\section{Catchment areas}

We have delineated the grounded catchment basins of WIS by combing two sources of data, Landsat imagery to map ice divides and contours on topographic maps. We find the total area of WIS to be $16200 \mathrm{~km}^{2}$ and the grounded catchment area which feeds it to be $16900 \mathrm{~km}^{2}$. Thus an unusually low proportion of the catchment area sustaining WIS is grounded ice compared with George VI Ice Shelf $(3.5: 1)$ and Wordie Ice Shelf. In this respect WIS may be similar to Larsen Ice Shelf in being sustained largely by in situ accumulation.

\section{RADIO-ECHO SOUNDING}

Hundreds of $\mathrm{km}$ of airborne RES data have been collected over WIS during British Antarctic Survey field campaigns between 1966 and 1975 (Smith, 1972; Crabtree, 1983). Despite system performance proven capable of obtaining echoes through more than $2 \mathrm{~km}$ of pure glacier ice, only a few echoes were obtained over 


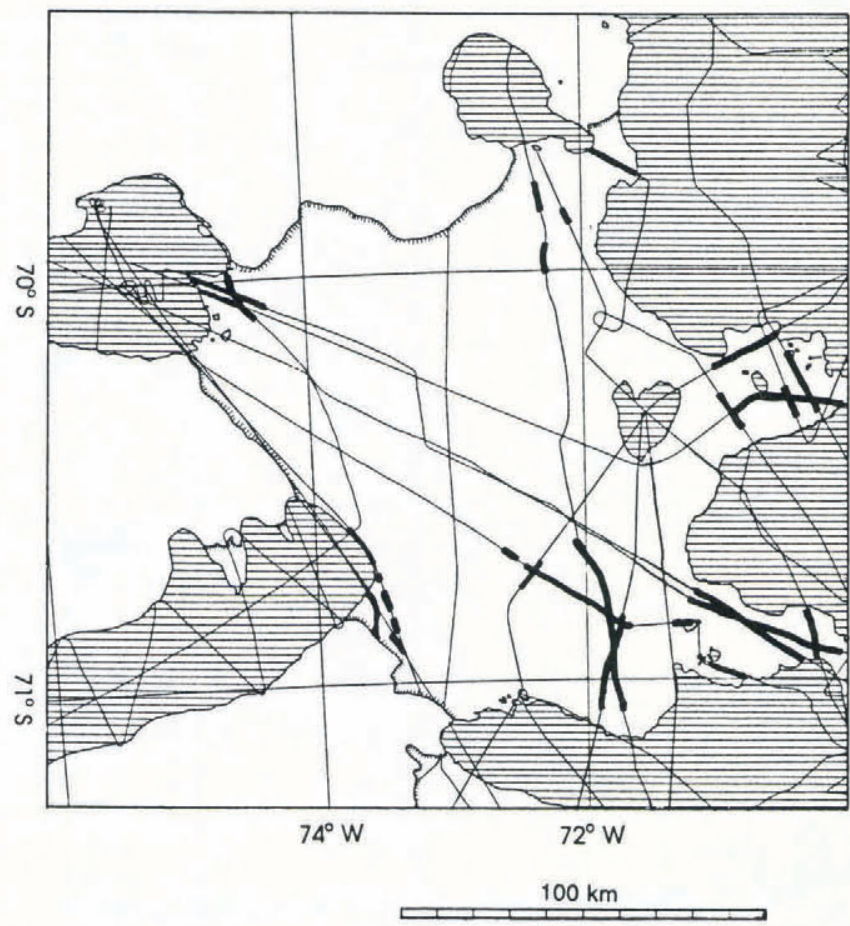

Fig. 4. RES flight paths over WIS. Over ice-shelf ice successful ice bottom-sounding is indicated by the bold line. Over grounded ice the ice bottom was successfully sounded almost continuously.

WIS (Fig. 4). Sounding was successful, however, over almost the entire area of the nearby Bach and George VI ice shelves and over almost the entire grounded region. Smith (1972) assumed the lack of echoes was due to seawater infiltration causing increased attenuation. WIS is in this respect unlike its neighbours.

Comparison of Figures 3 and 4 shows basal echoes were only obtained over areas which are associated with the elevated tongues from the inputs of grounded ice, namely the area close to Lewis Ice Field, upstream of the ice rises on Schubert and Haydn Inlets, on Dorsey Island, and from the small catchment on Charcot Island. Only a few scattered echoes were obtained over the rest of the ice shelf and these tend to be weak, their character unlike that from a normal ice-shelf base. We concur with Smith that these returns originate from some internal horizon, possibly associated with brine infiltration.

The distribution of successful RES has shown that basal echoes are obtained only through ice that accumulated on the grounded catchment zone. Where the ice shelf is sustained primarily by in situ accumulation, reflections are not obtained. Ice achieves pore closeoff, due to age and overburden stress, at between 40 and $70 \mathrm{~m}$ depth, below which it ceases to be porous. If the ice reaches pore close-off before it becomes the basal layers of the ice shelf, it will not become saturated with sea water unless basal crevasses are present to provide a route through this otherwise impervious layer. Snow falling on the surface is thus unlikely to have reached pore close-off before it reaches sea level. If the ice below sea level is already flooded with sea water, then the hydrostatic pressure will act to maintain the open pores and disrupt the densification process. In this regime ice may never achieve pore close-off despite the ice-shelf thickness reaching 200 to $300 \mathrm{~m}$. The ice may thus remain porous throughout the ice thickness and sea water continue to infiltrate.

\section{GEOSAT DATA}

The classified GEOSAT Geodetic Mission (GM) took place between 1 April 1985 and 30 September 1986, during which period the satellite was placed in a nonrepeating orbit with the aim of densely mapping the marine geoid. The ground track spacing obtained was of the order of 2 to $3 \mathrm{~km}$ at $60^{\circ} \mathrm{S}$, decreasing further south. The GM data are thus considerably denser than the previously available 17-day repeat data already used by various authors (e.g. Zwally and others, 1989) for glaciological applications.

Much of the GM data over the Antarctic land mass was eliminated by quality checking based on sensor flags indicating poor surface tracking. However, in areas where radar echo waveforms fit the criteria demanded by the on-board tracking algorithms, land and ice-shelf data have been retained. These data are mostly from areas of low surface slope, typically ice shelves, where the surface characteristics lead to ocean-like returns. The raw GEOSAT data were processed by the NOAA facility at Johns Hopkins University Astro-Physical Laboratory into Geophysical Data Records (GDRs). These records include height data the full $10 \mathrm{~Hz}$ sampling rate every $670 \mathrm{~m}$ along track on the surface. The orbits for the GM were computed by the Naval Surface Weapons Centre (NSWC) using computational procedures described by Smith and others (1987). The mean error in satellite height, as estimated from the orbit crossover differences over WIS, is found to be $40-80 \mathrm{~cm}$. However, extreme outliers in the crossover analysis are observed to exhibit errors of 10 to $20 \mathrm{~m}$. Taking into account tracking errors, we consider ellipsoidal height data to be accurate to within $2 \mathrm{~m}$. Crossover analysis confirms this estimate and indicates that it may well be conservative.

\section{GEOSAT data over WIS}

Various ice shelves have been studied using satellite altimeter data (Brooks and others, 1983; Zwally and others, 1987; Ridley and others, 1989). The performance of the on-board tracking algorithm and the morphology of the surrounding regions restricts the ice shelves that can be satisfactorily mapped by the GEOSAT radar altimeter. The altimeter is unable to track land surfaces where the surface slopes are greater than $1^{\circ}$ or the topographic relief is greater than $30 \mathrm{~m}$ in amplitude within the $7 \mathrm{~km}$ diameter radar footprint. For example, whilst coverage of the exposed WIS is quite extensive, that of the nearby George VI Ice Shelf, enclosed between two mountainous regions, is limited to a few spot meaurements near its centre.

Figure 5 shows data points acquired at $10 \mathrm{~Hz}$, with an along-track ground spacing of $670 \mathrm{~m}$, across the ice shelf and surrounding regions. Areas of missing data show where the altimeter failed to acquire or maintain lock on the surface. 


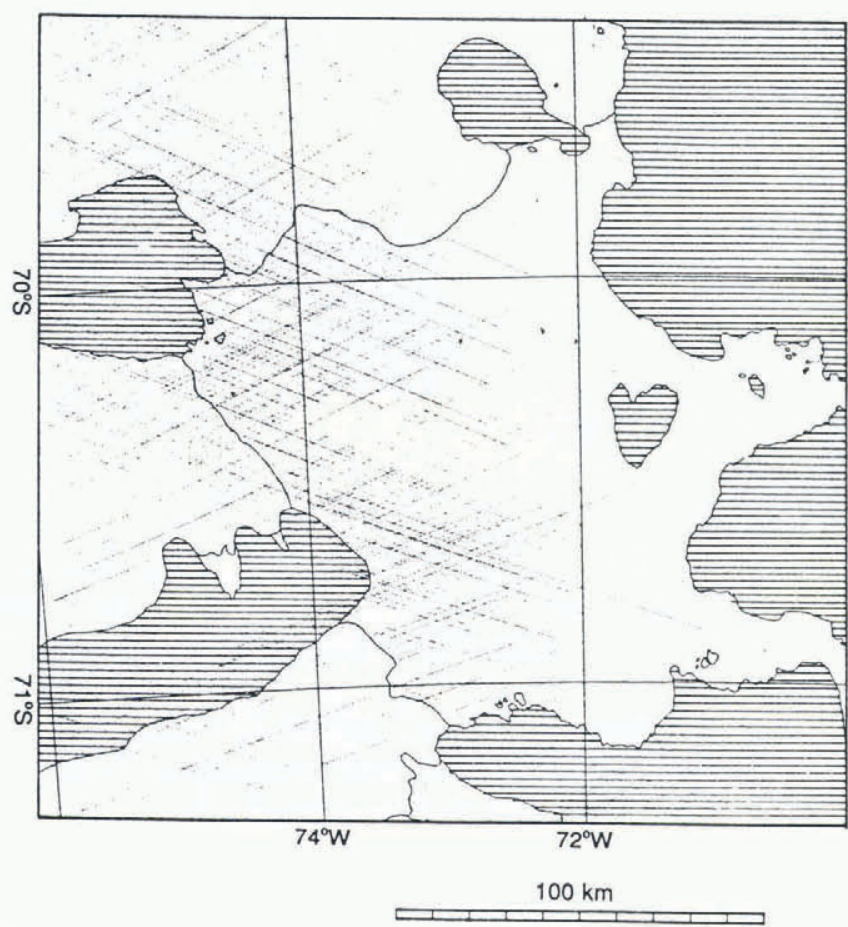

Fig. 5. Coverage of GEOSAT GM data.

The primary product from the GEOSAT data has been a map of surface topography. Figure 6 shows the GEOSAT data over WIS relative to the WGS84 ellipsoid. The point data were bilinearly interpolated onto a regular $1 \mathrm{~km}$ grid using an $800 \mathrm{~m}$ search radiuses. This grid was then contoured at $2.5 \mathrm{~m}$ intervals. This process smooths the occasional inconsistent datapoint on the interior of the ice shelf but tends to blur the feature edges including the ice front.

\section{Tidal deflection}

Ice shelves are subject to vertical oscillation on the ocean tides. Satellite altimeter observations include the ocean tidal displacement which ought to be removed for precise work to give a common mean sea-level datum. Close to areas of grounding, however, the tidal deflection is reduced, so these areas should be identified before a tidal correction is applied.

No tidal measurements have been made on WIS. The nearest tidal records were presented by Cartwright (1979), who made a constituent analysis on records from George VI Ice Shelf, which is subject to local distortions due to its geometry, and from Debenham Islands. We cannot apply these constituents, obtained $300 \mathrm{~km}$ away, directly to WIS. In the absence of local data we apply the NSWC global tidal model (Swiderski, 1980-81), which is derived from a combination of mathematical models and empirical techniques. Cartwright's Debenham Island data appears to have been included in the derivation of the NSWC model, giving at least some control on the model in the area.

The NSWC model gives a maximum tidal amplitude over WIS of $1.2 \mathrm{~m}$, although average tidal amplitudes will be considerably smaller. The high density of GEOSAT geodetic mission tracks over WIS means that when gridding to $1 \mathrm{~km}$, data from many passes are included in the calculation of each grid value. It is thus likely that a large part of the variance in the GEOSAT elevations is due to tidal effects. The precision required for this study does not demand tidal such small corrections, but these will be made in a future study to determine a baseline elevation map for studies of ice-shelf change.

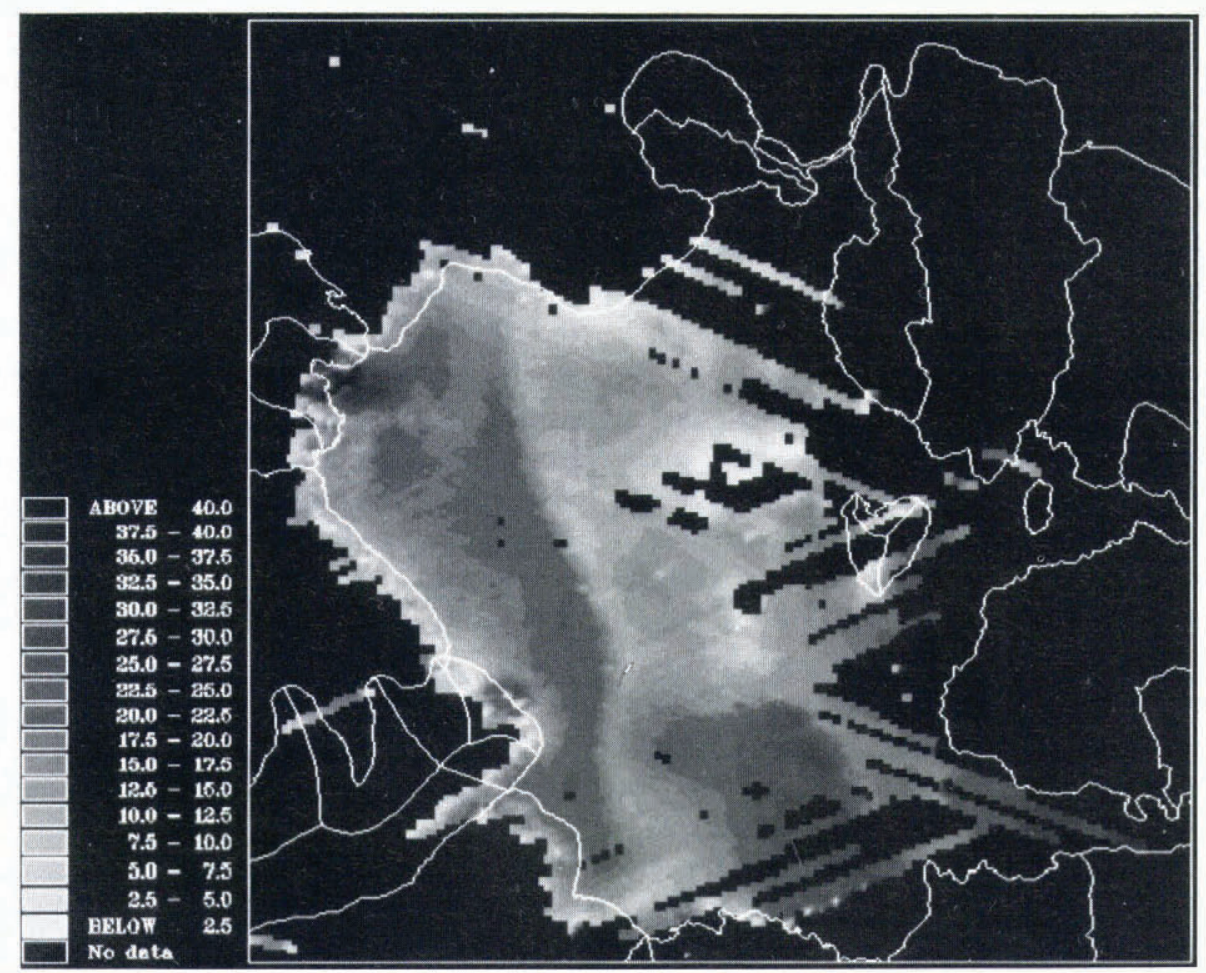

Fig. 6. GEOSAT ellipsoidal height map, with ice-shelf coast and catchment basins marked. 


\section{Artifacts in GEOSAT data}

Over homogeneous reflecting surfaces satellite radar altimeters range to the nearest surface point below the satellite. When this point is not at nadir, for example over a sloping surface, "off-ranging" occurs. For GEOSAT in the $800 \mathrm{~km}$ orbit, off-ranging contributes $2 \mathrm{~km}$ horizontal or $0.8 \mathrm{~m}$ vertical error for a $0.2 \%$ surface slope. These values increase to $8 \mathrm{~km}$ horizontal or $80 \mathrm{~m}$ vertical error for a $1 \%$ surface slope. Off-ranging always causes ellipsoidal height to be over-estimated. On WIS the surface gradients rarely exceed $0.2 \%$, so we have not applied any off-ranging correction in this study.

Over inhomogeneous reflecting surfaces satellite radar altimeters may track an echo from the brightest reflection within the footprint. Echoes from open water are usually stronger than those from ice shelf, hence close to the ice front the signal may be dominated by returns from the water. This phenomenon is known as "snagging" and can lead to under-estimates of surface elevation close to the ice front. This problem can be alleviated by "retracking" the return-echo waveforms (Martin and others, 1983), but for the GM waveform data are not available. In addition, the retracking process would be prohibitively time-consuming for the amount of data considered here. The GEOSAT data for WIS presented in this paper may thus be unreliable near ice fronts. The situation is further complicated by the presence of sea-ice and icebergs beyond the ice front, which give rise to contaminating returns. The effects of "snagging" are clearly present in Figure 6 over Latady and Charcot islands, where gradients away from the coast are clearly negative and incorrect.

\section{DISCUSSION}

\section{Comparison of Landsat and GEOSAT data}

The most obvious features on the ice shelf are two prominent bulges, one in the south and the other in the west (Fig. 6). The extremity of the southern bulge is strongly correlated with feature $\mathbf{C}$ observed from the Landsat imagery, and shows the steep gradients around the elevated tongue emanating from Lewis Ice Field. Features D and E, observed from the Landsat imagery, coincide with the extremity of the western bulge.

The western and southern bulges have a distinct trough running between them. It is thus unlikely that the western bulge is fed from Lewis Ice Field. The grounded catchment areas feeding the western bulge consist only of small areas on Latady Island $\left(350 \mathrm{~km}^{2}\right)$ and Charcot Island $\left(326 \mathrm{~km}^{2}\right)$. Flowlines indicate that most of the input from Charcot Island is diverted to the north by the small ice rumples/rises in its path, and leaves by the northern ice front. The western bulge is thus almost certainly sustained primarily by in situ accumulation.

The two surface depressions on the ice shelf coincide with the wakes downstream of ice rumples groups, I and $\mathrm{J}$. The feature $\mathrm{H}$ coincides with a local depression and is almost at sea level, it is the lowest point on the ice shelf shown by the GEOSAT data suggesting thtat there is a hole in the ice shelf at this point. To the south of

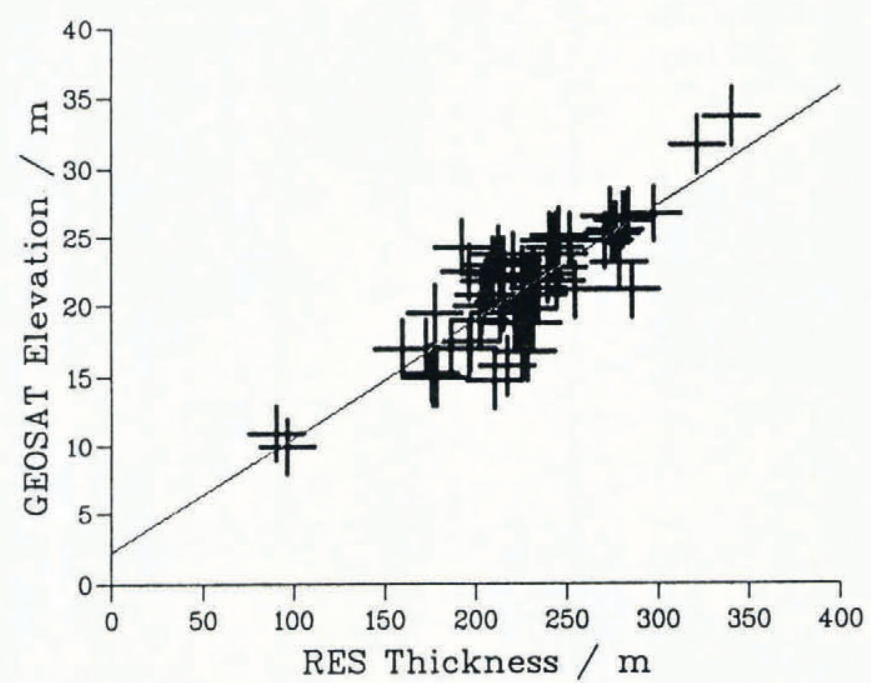

Fig. 7. Relation of GEOSAT (GEM-T1) elevation to RES thickness over WIS with error estimates given by the size of the crosses, with the linear regression line.

Rothschild Island there is an extensive area of ice shelf over which the altimeter consistently fails to maintain lock. The area coincides with the area of melt pools $(\mathrm{K}$, Fig. 3), and appears to be a result of the unusual surface topography in this area.

\section{Comparison of GEOSAT and RES data}

Contour plots of GEOSAT ellipsoidal height were produced using a procedure similar to that used for Figure 6 . We estimate this process introduces only $1 \mathrm{~m}$ of additional uncertainty into the ellipsoidal heights. We then overlaid our RES data and extracted ellipsoidal height values corresponding to each of the thickness measurements. For simplicity we have used only the RES values given by Crabtree (1983), which were calculated assuming a velocity of radio waves in ice of $169 \mathrm{~m} \mathrm{\mu s}^{-1}$ and making no firn-layer correction. These are believed to be accurate to $\pm 20 \mathrm{~m}$.

For a meaningful comparison with the ice thicknesses we must convert the GEOSAT ellipsoidal heights to approximate sea-level elevations using an appropriate geoidal mode. We have used the GEM-T1 geoidal model developed by Marsh and others (1988) from satellite tracking data. Across WIS the geoidal height for this model ranges from $-4.0 \mathrm{~m}$ in the south-west to $-1.5 \mathrm{~m}$ in the north-east. The correlation coefficient $\left(r^{2}\right)$ between elevation and thickness is improved from 0.55 to 0.70 by application of the GEM-T1 geoid.

Figure 7 shows the relation between GEOSAT (GEM-T1) elevation $(h)$ and RES ice thickness $(H)$. Linear regression of these data give

$$
h=(0.084 \pm 0.013) H+(2.2 \pm 3.0)
$$

where the uncertainties are given at the $95 \%$ confidence limit.

The gradient value derived here is lower than those derived for other ice shelves (e.g. Shabtaie and Bentley, 1982) and lower than the theoretical minimum gradient of 0.108 , calculated assuming a sea-water density of $1028 \mathrm{~kg} \mathrm{~m}^{-3}$ and a maximum density of ice of $917 \mathrm{~kg} \mathrm{~m}^{-3}$. 
This anomalous value indicates some failure of either the data or the model. Factors such as variations in the velocity of radio-waves in ice, brine infiltration or offranging errors are unlikely to cause cause a distortion. The most likely cause is inadequacy in the geoid model; although a $5 \mathrm{~m}$ error across the ice shelf $(200 \mathrm{~km})$ would be required to cause this effect. Ridley and others (1989) noted errors on the east of the Antarctic Peninsula of at least $1.3 \mathrm{~m}$.

\section{Accumulation measurements}

The north-south crest of Alexander Island almost certainly forms a significant climatic boundary between east and west of the island. We therefore do not consider accumulation measurements made on George VI Ice Shelf relevant to the WIS. There remain only a few measurements in the area of WIS. Peel and Clausen (1982) compiled accumulation measurements; of specific relevance are Charcot Island (elevation $595 \mathrm{~m}$ ) $1.69 \mathrm{~m} \mathrm{a}^{-1}$ (water equivalent) and the western end of Monteverdi Peninsula (elevation $488 \mathrm{~m}$ ) $0.91 \mathrm{~m} \mathrm{a}^{-1}$ (water equivalent). Mulvaney (personal communication) measured accumulation on the western tip of Beethoven Peninsula (elevation $580 \mathrm{~m}$ ) to be around $1.0 \mathrm{~m} \mathrm{a}^{-1}$ (water equivalent).

The only data from WIS itself are from accumulation stake and density pit measurements at J8. Over the 325 day interval between January and December 1972, accumulation was $(0.50 \pm 0.06) \mathrm{m}$ (water equivalent). Similar data over a 315 day interval on Bach Ice Shelf gave around $(0.32 \pm 0.04) \mathrm{m}$ (water equivalent). Thus the ice-shelf values are considerably lower than those given above.

The data are too sparse to extract any geographical trend reliably. They are, however, compatible with the thesis that the prevailing moisture transport from the Bellingshausen Sea causes unusually high accumulation rates close to the western sea-board.

\section{Mass balance regime}

Basal melt-rates under WIS are likely to be a significant component in the mass balance regime but there are no measured values. We assume, by comparison with the nearby George VI Ice Shelf (Pearson and Rose, 1983), that the rates are high $\left(1-2 \mathrm{~m} \mathrm{a}^{-1}\right)$.

As we have observed, the grounded catchment area of WIS is unusally small in comparison to the ice-shelf area. Together with the increased snowfall close to the open sea, this implies that much less than $50 \%$ of the ice in WIS is derived from the grounded catchment area, which is confirmed by the RES data.

The major unexplained feature in the GEOSAT data is the western bulge which, as we have stated previously, does not appear to be sustained by horizontal transport. This feature might be the result of either anomalously high accumulation or low basal melt rates, but at present we cannot determine which.

The accumulation data are compatible with enhanced snowfall close to the western seaboard, but if this were the cause we might expect the highest accumulation and hence the thickest ice to be close to the ice front. This is not the case, as the thickness increases slowly inland to its maximum and than falls off steeply. We cannot discount the possiblity that westerly katabatic winds from the crest of Alexander Island cause significant redistribution of snowfall on the ice shelf, but no data relating to prevailing winds are available. The presence of many ice rises/ rumples is an indication of a complex bedrock topography beneath the ice shelf suggesting that the ocean currents may be equally complex. There is thus also a possibility of an area of reduced basal melting causing the western bulge.

\section{CONGLUSIONS}

Until this study little was known about WIS. For various reasons little ground-based work had been attempted, and despite repeated airborne RES campaigns, few basal returns were obtained. GEOSAT Geodetic Mission data has given us an excellent surface elevation/thickness map which shows much structure. Contrast-stretched Landsat TM imagery has proved to be a significant improvement on the earlier Landsat MSS photographic product. The distribution of successful RES has shown the extent of the glacier ice and in situ accumulation. We now have a good structural model of WIS on which to base further studies. The mechanism producing the enigmatic western bulge shown by the GEOSAT data cannot, however, be determined by the remotely sensed data presented here. We must wait for further surface and oceanographic measurements to unravel its origin.

We have shown that WIS is unusual for an Antarctic ice shelf in that it derives most of its sustenance from in situ accumulation and has low horizontal velocities. It may thus respond to climate change in a very different way compared with ice shelves fed by dynamic outlet glaciers. For instance, Wordie Ice Shelf began disintegrating by calving along its ice front while enhanced fracture processes were weakening its interior. After the ice front had retreated past a critical limit, the outlet glaciers were able to punch through the remaining ice shelf because of the reduced restraint on them. The lack of such fast-flowing glaciers entering WIS means that a component important in the disintegration of Wordie Ice Shelf is absent. The ice front of WIS is likely to decay by normal calving processes, which at present are still largely unknown, but there is unlikely to be the sudden disintegration seen on the Wordie, at least until the calving front decouples from the fringing islands. Changes in accumulation and basal melting rates may, however, dominate any dynamic effects.

\section{ACKNOWLEDGEMENTS}

Our thanks to colleagues at British Antarctic Survey and Mullard Space Science Laboratory, especially Rick Frolich and Liz Morris, and to Andy Bingham of Oxford University, for providing the GEM-T1 data.

\section{REFERENCES}

Brooks, R. L., R. S. Williams, Jr, J. G. Ferrigno and W. B. Krabill. 1983. Amery Ice Shelf topography from satellite radar altimetry. In Oliver, R. L., P. R. James 
and J. B. Jago, eds. Antarctic earth science. Cambridge, etc., Cambridge University Press, 441-445.

Cartwright, D.E. 1980. Analyses of British Antarctic Survey tidal records. Br. Antarct. Surv. Bull. 49, 167179.

Crabtree, R. D. 1983. Ice thickness map of Alexander Island. 1:500 000. Cambridge, British Antarctic Survey.

Doake, C.S.M. and D. G. Vaughan. 1991. Rapid disintegration of the Wordie Ice Shelf in response to atmospheric warming. Nature, 350(6316), 328-330.

Marsh, J.G. and 19 others. 1988. A new gravitational model for the Earth from satellite tracking data: GEMT1. 7. Geophys. Res., 93(B6), 6169-6215.

Martin, T. V., H.J. Zwally, A. C. Brenner and R.A. Bindschadler. 1983. Analysis and retracking of continental ice sheet radar altimeter waveforms. $\mathcal{J}$. Geophys. Res., 88(C3), 1608-1616.

Mercer, J.H. 1978. West Antarctic ice sheet and $\mathrm{CO}_{2}$ greenhouse effect: a threat of disaster. Nature, 271(5643), 321-325.

Morrison, S.J. 1990. Warmest year on record on the Antarctic Peninsula? Weather, 45(6), 231-232.

Pearson, M.R. and I.H. Rose. 1983. The dynamics of George VI Ice Shelf. Br. Antarct. Surv. Bull. 52, 205220.

Peel, D. A. and H. B. Clausen. 1982. Oxygen-isotope and total beta-radioactivity measurements on $10 \mathrm{~m}$ ice cores from the Antarctic Peninsula. J. Glaciol., 28(98), 43-55.

Reynolds, J. M. 1981. The distribution of mean annual temperatures in the Antarctic Peninsula. Br. Antarct. Surv. Bull. 54, 123-133.
Ridley, J., W. Cudlip, N. McIntyre and C. Rapley. 1989. The topography and surface characteristics of the Larsen Ice Shelf, Antarctica, using satellite altimetry. 7. Glaciol., 35(121), 299-310.

Sansom, J. 1989. Antarctic surface temperature time series. 7. Climate, 2, 1164-1172.

Shabtaie, S. and C. R. Bentley. 1982. Tabular icebergs: implications from geophysical studies of ice shelves. $\mathcal{J}$. Glaciol., 28(100), 413-430.

Smith, B. M. E. 1972. Airborne radio echo sounding of glaciers in the Antarctic Peninsula. Br. Antarct. Surv. Sci. Rep. 72.

Smith, S. L., G.B. West and C.W. Malyevac. 1987. Determination of ocean geodetic data from GEOSAT. Johns Hopkins APL Technical Digest, 8(2).

Swiderski, E. W. 1980-1981. Global ocean tides. Parts II to $X$. Dahlgren, VA, Naval Surface Weapons Center. (Technical Reports 79-414, 81-122, 81-142, 81-144, 81-218, 81-220.)

Swithinbank, C. 1988. Satellite image atlas of glaciers of the world: Antarctica. U.S. Geol. Surv. Prof. Pap. 1386B.

Zwally, H.J., S. N. Stephenson, R.A. Bindschadler and R. H. Thomas. 1987. Antarctic ice-shelf boundaries and elevations from satellite radar altimetry. Ann. Glaciol., 9, 229-235.

Zwally, H.J., A. C. Brenner, J. A. Major, R. A. Bindschadler and J. G. Marsh. 1989. Growth of Greenland ice sheet: measurement. Science, 246(4937), 1587-1589.

The accuracy of references in the text and in this list is the responsiblity of the authors, to whom queries should be addressed. 